\title{
Cardiac Tachyarrhythmias in Hereditary Long QT Syndromes Presenting as a Seizure Disorder
}

\author{
M.B.M. Sundaram, J.D. McMeekin and S. Gulamhusein
}

\begin{abstract}
Patients with hereditary long QT disorders - Romano-Ward Syndrome and Jervell Lange-Nielsen Syndrome - sometimes present with seizures due to cardiac tachyarrhythmias. Two such patients are presented, emphasizing diagnostic clues - syncope, seizures with onset in early life, precipitation of attacks by emotional or physical stress, positive family history of sudden death and/or seizures, normal EEG and prolonged QT interval on ECG. Treatment is usually with adequate doses of sympathetic betablockers.
\end{abstract}

\begin{abstract}
RÉSUMÉ: La tachyarythmie cardiaque dans les syndromes du QT prolongé se manifestant par des crises convulsives. Les patients qui présentent des affections héréditaires caractérisées par un intervalle QT anormalement long - le syndrome de Romano-Ward et le syndrome Jervell Lange-Nielsen - consultent parfois pour des convulsions dues à une tachyarythmie cardiaque. Nous présentons les cas de deux de ces patients en insistant sur les indices diagnostiques - la syncope, les crises convulsives débutant dans le jeune âge, le déclanchement des crises par le stress émotionnel ou physique, une histoire familiale de mort subite et/ou de crises convulsives, un EEG normal et un intervalle QT prolongé à l'ECG. Des doses adéquates de betabloquants sympathiques constituent le traitement habituel de ce problème.
\end{abstract}

Can. J. Neurol. Sci. 1986; 13:262-263

In 1957, Jervell and Lange-Nielsen described autosomal recessive syndrome in children as characterised by prolonged QT interval, ventricular tachyarrhythmias, and clinical manifestations of syncope, congenital deafness and sometimes sudden death. A similar congenital disorder with autosomal dominant inheritance but without deafness was recognized independently by Romano in $1963^{2}$ and Ward in $1964 .^{3}$ These hereditary prolonged QT syndromes have since been described in the literature as "Jervell-Lange-Nielsen Syndrome" (JLNS) and "Romano-Ward Syndrome"' (RWS). Patients sometimes present with seizures due to cardiac tachyarrhythmias ${ }^{4,5,6}$ and recognition of these potentially fatal but treatable disorders by neurologists is important. We present index patients from two families - one with RWS, the other with JLNS - to illustrate clinical features and diagnostic clues with a brief discussion on management.

\section{CaSe Reports}

Case 1: This 33-year-old woman was referred to the Neurology Department for assessment following 3 seizures between the ages of 5 and 33 .
These were characterized by stiffening of the body and limbs, jerking of the upper limbs, cyanosis and urinary incontinence. Each attack lasted approximately two minutes. The third episode occurred while the telephone was ringing and other attacks during sleep. Three of her six siblings died suddenly during sleep between the ages of 12 and 22 years; two of them had prior history of chronic recurrent seizures. The patient's 12-year-old daughter suffered "blackouts" and documented ventricular tachycardia from infancy; her attacks were characterized by stiffening, urinary incontinence and pallor.

Neurological examination, blood electrolytes, EEG and CT scan of the brain were normal. ECG monitoring during EEG suggested long QT interval and subsequent 12-lead ECG confirmed a prolonged QT interval. Her 80-year-old mother was found to have a prolonged QT interval. We were also able to document prolonged QT and attacks of ventricular arrhythmias associated with syncope in the patient's 12-year-old daughter. (Figure).

The patient remains seizure-free on Propranolol. Her daughter was given the same medication, but subsequently required atrial pacing because of profound bradycardia.

Case 2: This 17-year-old congenitally deaf girl presented with recurrent blackouts since 18 months of age. These consisted of generalized stiffening, jerking, cyanosis, and at times urinary incontinence. Most attacks were precipitated by minor emotional stress. One such attack in the hospital was documented and associated with ventricular fibrillation.

Presented in part at the XX Canadian Congress of Neurological Sciences, Montreal, June, 1985

From the Departments of Clinical Neurological Sciences and Medicine, University of Saskatchewan, Saskatoon, Saskatchewan

Received November 15, 1985. Accepted March 12, 1986

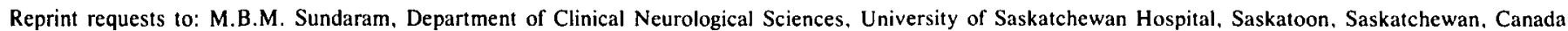
S7N 0X0 


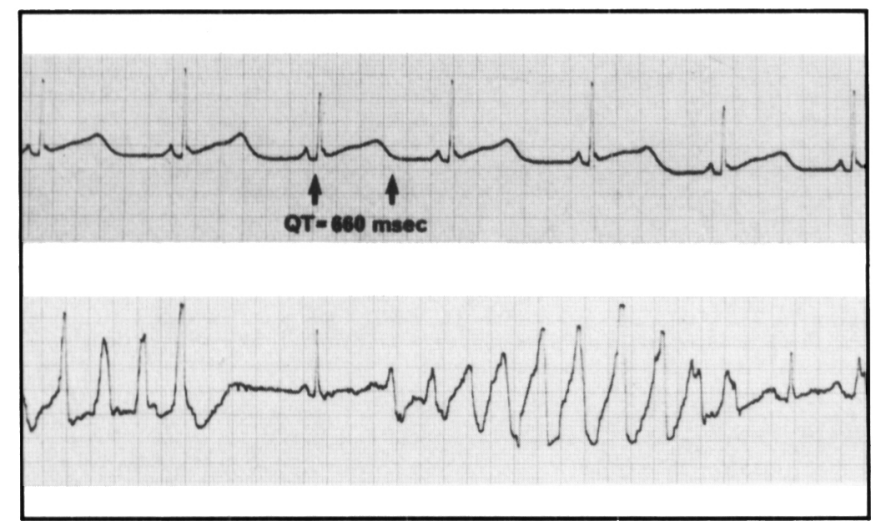

Figure I - Electrocardiogram rhythm strip of 12-year-old daughter of Case 1. Lead II: upper tracing shows normal sinus rhythm with prolonged QT interval: lower tracing shows typical episodes of ventricular arrhythmia (Torsade de pointes). Paper speed $25 \mathrm{~mm} / \mathrm{sec}$.

Two of her cousins, one paternal and the other maternal, were deaf; one of them had seizures and died suddenly at 21 years during an apparent seizure. The patient's parents shared a common great grandfather.

Neurologic examination showed bilateral nerve deafness. Blood electrolytes and EEG were normal. ECG monitoring during EEG showed a prolonged rate corrected QT of approximately 500 milliseconds (normal: 400 milliseconds). This was subsequently confirmed by a regular 12-lead ECG. She has responded well to Propranolol.

\section{Discussion}

Recognition of RWS and JLNS among seizure patients is important to prevent potential mortality both in patients and their relatives. Diagnostic clues include: i) onset of syncope and/or cardiogenic seizures in childhood and teens, ${ }^{7.8}$ ii) family history of syncope, seizures and sudden death, iii) normal EEG with prolonged QT interval on ECG. Patients with JLNS, in addition, are congenitally deaf. The ECG should be routinely monitored during EEG in these patients with attention to the QT interval. QT can be recognized from the EEG paper in approximately $2 / 3$ of tracings and measurements greater than 400 milliseconds (two divisions at usual paper speed of 30 millimeters per second) are suspicious. However, accurate measurements and confirmation of long QT interval should be based on regular 12 lead ECG. QT interval may be prolonged in a variety of non-hereditary disorders including myocardial ischemia, cardiomyopathy, mitral valve prolapse, electrolyte and metabolic abnormalities such as hypokalemia, hypocalcemia, hypomagnesaemia; antiarrhythmic drugs like quinidine, disopyramide, procainamide; tricyclic antidepressants and phenothiazines. ${ }^{9,10}$ Age and sex also affect QT interval.

A positive family history of syncope and seizures is not unique to RWS and JLNS, but may also be present in patients with congenital and adult onset heart block."

Seizures and syncope in RWS and JLNS are due to sudden ventricular tachyarrhythmias with resulting impairment of cerebral perfusion. These arrhythmias are considered responsible for sudden death. The mechanism of prolonged QT interval in these syndromes is not established but has been proposed to result from asymmetric stimulation of the heart by right and left sympathetic chains. ${ }^{12-14}$ Prolongation of the QT interval, reduc- tion of the threshold for ventricular fibrillation and enhancement of ventricular excitability occur in experimental animals and humans following stimulation of left stellate ganglion or right stellate ganglionectomy. ${ }^{12-16}$ Precipitation of tachyarrhythmias and syncope in RWS and JLNS by emotional outbursts, stress and exercise is well recognized ${ }^{7.10}$ and might support the role of the sympathetic nervous system in these disorders.

Betablocker therapy is used initially in most cases to prevent tachyarrhythmias and has been shown to reduce mortality. ${ }^{7}$ Phenytoin ${ }^{7.8}$ and left sympathetic ganglionectomy ${ }^{15}$ are useful in propranolol-resistant cases. In intractable cases, atrial overdrive pacing devices capable of automatic cardioversion and defibrillation should be considered.

Frequency of RWS and JLNS among seizure patients is not known, but is likely small. However, Schott et al, ${ }^{17}$ noted that cardiac arrhythmias from various causes contributed to seizures in $20 \%$ of their patients with "idiopathic" epilepsy and emphasized the importance of 24-hour ECG monitoring to detect arrhythmias.

\section{REFERENCES}

1. Jervell A, Lange-Nielsen F. Congenital deaf-mutism, functional heart disease with prolongation of the Q-T interval and sudden death. Am Heart J 1957; 54: 59-68.

2. Romano C, Lemme G, Pongiglione R. Aritmie cardiache rare dell'eta' pediatrica. Clinica Paediatrica 1963: 45: 656-683.

3. Ward OC. A new familial cardiac syndrome in children. J Irish Med Assoc 1964; 54: 103-106.

4. Singer PA, Crampton RS, Bass NH et al. Familial Q-T prolongation syndrome. Arch Neurol 1974; 31: 64-66.

5. Selby PJ, Driver MV. An unusual cause of apparent epilepsy: ECG and EEG findings in a case of Jervell Lange-Nielsen syndrome. J Neurol Neurosurg Psychiatry 1977; 40: 1102-1108.

6. Ballardie FW, Murphy RP, Davis J. Epilepsy: A presentation of the Romano-Ward syndrome. Br Med J 1983; 287: 896-897.

7. Schwartz PJ, Periti M, Malliani A. The long Q-T syndrome. Am Heart J 1975; 89; 378-390.

8. Ratshin RA, Hunt D, Russell RO et al. Q-T interval prolongation, paroxysmal ventricular arrhythmias and convulsive syncope. Ann Intern Med 1971; 75: 919-924.

9. Moss AJ, Schwartz PJ, Crampton RS et al. The long Q-T syndrome: A prospective international study. Circulation 1985; 71: 17-21.

10. James TN. Q-T prolongation and sudden death. Mod. Concepts Cardiovasc Dis 1969; 38: 35-38.

11. Sarachek NS, Leonard JJ. Familial heart block and sinus bradycardia. Am J Cardiol 1972; 29: 451-458.

12. Schwartz PJ, Malliani A. Electrical alteration of the T-wave: Clinical and experimental evidence of its relationship with the sympathetic nervous system and with the long Q-T syndrome. Am Heart J 1975; 89: 45-50.

13. Han J, Moe GK. Nonuniform recovery of excitability in ventricular muscle. Circ Res 1964; 14: 44-60.

14. Yanowitz F, Preston JB, Abildskor JA. Functional distribution of right and left stellate innervation to the ventricles. Circ Res 1966; 18: 416-428.

15. Moss AJ, McDonald J. Unilateral cervicothoracic sympathetic ganglionectomy for the treatment of long Q-T interval syndrome. N Engl J Med 1971; 285: 903-904.

16. Hugenholtz PG. Electrocardiographic changes typical for central nervous system disease after right radical neck dissection. Am Heart J 1967; 74: 438-441.

17. Schott GD, McLeod AA, Jewitt DE. Cardiac arrhythmias that masquerade as epilepsy. Br Med J 1977; i: 1454-1457. 